\title{
Tetramethylguanidine Covalently Bonded onto Silica Gel as Catalyst for the Addition of Nitromethane to Cyclopentenone
}

\author{
Edimar DeOliveira, Jocilene D. Torres, Carlos C. Silva, Afrânio A. M. Luz, Peter Bakuzis and \\ Alexandre G. S. Prado*
}

Instituto de Química, Universidade de Brasília, CP 4478, 70904-970 Brasília-DF, Brazil

\begin{abstract}
Um catalisador baseado em sílica quimicamente modificada com tetrametilguanidina (TMG) foi sintetizado pela co-condensação de tetraetilortossilicato (TEOS) com um novo agente sililante, preparado pela reação entre a molécula TMG e (3-cloropropil)trimetoxisilano. O direcionador n-dodecilamina foi utilizado para organizar a polimerização do catalisador inorgânico-orgânico. A termogravimetria mostrou que o número de sítios ativos do catalisador foi de $1,35 \mathrm{mmol} \mathrm{g}$, com uma área superficial de $811 \pm 75 \mathrm{~m}^{2} \mathrm{~g}^{-1}$. A espectroscopia na região do infravermelho e de ressonância magnética nuclear no estado sólido para os núcleos ${ }^{29} \mathrm{Si}$ e ${ }^{13} \mathrm{C}$ confirmou a obtenção do produto desejado. Este material foi usado para catalisar a adição de nitrometano em ciclopentenona. $98 \%$ de conversão foi observada depois de $3 \mathrm{~h}$ de reação. $\mathrm{O}$ catalisador foi recuperado e reutilizado por mais catorze vezes, mantendo uma eficiência catalítica em torno de $98 \%$.
\end{abstract}

A catalyst based on silica chemically modified with tetramethylguanidine (TMG) was synthesized by the co-condensation of tetraethylorthosilicate (TEOS) with a new silylant agent derived from the reaction between the TMG molecule and (3-chloropropyl)trimethoxysilane. A neutral $n$-dodecylamine template was used to organize the polymerization of the inorganicorganic catalyst. Thermogravimetry showed that the number of active pendant groups in the catalyst was $1.35 \mathrm{mmol} \mathrm{g}^{-1}$, with a surface area of $811 \pm 75 \mathrm{~m}^{2} \mathrm{~g}^{-1}$. Infrared spectroscopy and ${ }^{13} \mathrm{C}$ and ${ }^{29} \mathrm{Si}$ nuclear magnetic resonance data are in agreement with the proposed structure. This material has been used to catalyse the addition of nitromethane to cyclopentenone. The catalytic efficiency was followed and the nitromethylcyclopentanone conversion presented a yield of $98 \%$ at $3 \mathrm{~h}$ of reaction. The catalyst was recovered and reused 14 times, maintaining about $98 \%$ of its catalytic efficiency.

Keywords: silica, tetramethylguanidine, Michael addition, nitroalkane

\section{Introduction}

One of the most useful methods to produce a large variety of nitroalkanes is the formation of $\mathrm{C}-\mathrm{C}$ bonds by conjugate addition of nitroalkanes to enones (Michael addition). The relatively high acidity of the nitro group and its facile transformation into various functionalities have extended the importance of nitro compounds and these have proven to be valuable intermediates for the preparation of complex molecules ${ }^{1-5}$ and to serve as precursors, extensively used in the agrochemical, pharmaceutical and dyestuff industries. ${ }^{6}$

Thus, a great interest in these kinds of synthetic processes has been shown in recent years. In this direction, conjugate addition of nitroalkanes to $\alpha, \beta$-unsaturated

*e-mail: agspradus@gmail.com ketones in the presence of catalytic amounts of bases has been extensively reported. ${ }^{7,8}$

The Michael reactions of nitroalkanes are usually carried out in the presence of a variety of different bases in homogeneous solutions of organic solvent or water. ${ }^{9}$ Alternatively, heterogeneous catalysis ${ }^{10,11}$ has been studied in order to take advantage of easy recovery of the catalyst and its reapplication in the chemical process, consequently minimizing the amount of waste products. Indeed, heterogeneous catalytic processes are one of the key goals for the development of clean synthetic methods.

Among various supports used to obtain heterogeneous catalysts, silica gel has been highlighted, since this inorganic material supersedes organic carrier polymers with technological advantages such as high surface area, insolubility in organic and aqueous solvents, thermal and mechanical stabilities, and swelling behaviour. ${ }^{12,13}$ The 
development of inorganic-organic hybrids by supramolecular neutral templating procedures typically employs some form of micelle to guide the formation of the hybrid with porous solid structures on a nanometer scale. ${ }^{14-16}$ This method results in mesoporous silicates, while the available organic pendant groups are useful for heterogeneous catalysis. ${ }^{17,18}$

In this direction, the present investigation reports a methodology for the attachment of tetramethylguanidine to silica gel by a co-condensation process and applies this material in catalyzing the addition of nitromethane to cyclopentenone.

\section{Experimental}

\section{Chemicals}

The silica source for the inorganic framework formation was derived from tetraethylorthosilane (TEOS). The silylant agent, chloropropyltrimethoxysilane ( $\mathrm{SiCl})$, tetramethylguanidine (TMG), the surfactant $n$-dodecylamine, triethylamine, methanol and ethanol were all reagent grade.

\section{Synthesis of the new silylant}

$4.35 \mathrm{~mL}$ of $\mathrm{SiCl}$ and $3.0 \mathrm{~mL} \mathrm{~g}$ of TMG were added to $20.0 \mathrm{~mL}$ of methanol containing $3.3 \mathrm{~mL}$ of triethylamine. The solution was stirred mechanically under dry nitrogen at $50{ }^{\circ} \mathrm{C}$ for $24 \mathrm{~h}$, then filtered in an inert atmosphere to separate the triethylammonium chloride formed. The new silylant agent is denoted as SiTMG and was used below without removing the methanol.

\section{Catalyst preparation}

The catalyst was prepared by stirring $13.0 \mathrm{~g}$ of $n$-dodecylamine in $200.0 \mathrm{~mL}$ of water/ethanol $(3: 1 \mathrm{v} / \mathrm{v})$ for 30 min until an opalescent solution was obtained, a consequence of micelle formation. To this micellar suspension were added $20.0 \mathrm{~mL}$ of TEOS and the methanol solution of the organosilane SiTMG prepared above. This suspension was stirred for $48 \mathrm{~h}$ at room temperature, resulting in a precipitate that was removed by filtration. The $n$-dodecylamine inside the pores of the synthesized compound was extracted with ethanol at reflux temperature for $72 \mathrm{~h}$ in a Soxhlet system and dried in vacuum at $25^{\circ} \mathrm{C}$ to obtain the final product named CatTMG.

\section{Characterization}

The amount of organic pendant chains co-condensed in the catalyst, CatTMG, was determined by thermo- gravimetric analysis from the residual data, which were obtained from an approximately $10 \mathrm{mg}$ CatTMG sample examined with a thermogravimetric analyzer, model TA2960, in a dynamic atmosphere using a dry nitrogen flux, with heating from room temperature up to $1000{ }^{\circ} \mathrm{C}$ at a heating rate of $10{ }^{\circ} \mathrm{C} \mathrm{min}^{-1}$. The surface area of the catalyst was calculated by using the BET equation. The isotherms of nitrogen adsorption at $77 \mathrm{~K}$ were obtained by means of a Micromerimetics Flowsorb 2300 analyzer. Infrared spectra of all samples were performed in $\mathrm{KBr}$ pellets in the $4000-400 \mathrm{~cm}^{-1}$ region with a resolution of $4 \mathrm{~cm}^{-1}$, by accumulating 32 scans using a MB-100 Bomem FTIR spectrophotometer. ${ }^{29} \mathrm{Si}$ and ${ }^{13} \mathrm{C}$ nuclear magnetic resonance spectra of the solid sample were obtained on a Varian Mercury Plus 300 spectrometer at room temperature. For each run, approximately one gram of catalyst was compacted into a $7 \mathrm{~mm}$ silicon nitrite rotor. The measurements were obtained at frequencies of 75.47 and $59.61 \mathrm{MHz}$, for carbon and silicon, respectively, with a magic-angle spinning speed of $3 \mathrm{kHz}$. In order to increase the signal to noise ratio of the solid-state spectra, the $\mathrm{CP} /$ MAS technique was used. ${ }^{29} \mathrm{Si}$ and ${ }^{13} \mathrm{C} \mathrm{CP} / \mathrm{MAS}$ spectra were obtained with pulse repetitions of $1 \mathrm{~s}$ and $2 \mathrm{~s}$ and contact times of 1 and $4 \mathrm{~ms}$, respectively. ${ }^{19}$

\section{Addition of nitromethane to cyclopentenone}

A mixture of $0.30 \mathrm{~mL}$ (3.6 mmol) of cyclopentenone and $0.20 \mathrm{~mL}(3.7 \mathrm{mmol})$ of nitromethane in the presence of $0.50 \mathrm{~g}$ of catalyst CatTMG in $10.0 \mathrm{~mL}$ of ethanol was stirred at $50{ }^{\circ} \mathrm{C}$ up to the end of the reaction. The catalyst was removed from solution by filtration and the crude product was purified by column chromatography on silica gel using hexane/ethyl acetate $(85: 15 \mathrm{v} / \mathrm{v})$ as eluant. The product was characterized by ${ }^{1} \mathrm{H}$ NMR at a frequency of $300 \mathrm{MHz}$ in $\mathrm{CDCl}_{3}$ as solvent on a Varian Mercury Plus 300 spectrometer at room temperature.

The amount of 3-nitromethylcyclopentanone produced was determined on a HPLC system, Perkin Elmer Series 200 equipped with LC Series 200 pump, Series 200 UVVis detector, and a Spheri-5 RP-18 column with partial size $5 \mu \mathrm{m}$. Manual injection was carried out with a $20 \mu \mathrm{L}$ loop, using water/methanol $(60: 40, \mathrm{v} / \mathrm{v})$ as the mobile phase. All analysis were done in triplicate.

\section{Kinetics studies}

The kinetic studies was carried out under the same conditions as described above, and the reactions were analysed after 5, 10, 15, 30, 60, 90, 120, 150, 180 and 300 minutes. 


\section{Recycling of CatTMG}

After each reaction, the CatTMG catalyst was filtrated and washed with ethanol and then it was reused in another mixture of cyclopentenone and nitromethane in order to perform the same reaction several times.

\section{Results and Discussion}

\section{Synthesis and characterization of the catalyst}

The attachment of guanidines to the variety of organic polymer supports for the transesterification of vegetable oils has been reviewed by Schuchardt et al.,${ }^{20}$ but these suffer from problems of leaching. Several types of guanidines have been anchored onto silica gels and their preparation and application have been compiled in reviews dealing with supported catalysis on mesoporous silicas. ${ }^{21}$ Many of these suffer from significant decreases in activity upon reuse and only one, ${ }^{22}$ to our knowledge, reports the synthesis of a tetramethylguanidine silica by a cocondensation methodology. The latter material was only partially characterized and was shown to the significantly less reactive upon reuse (but the reactions under study, epoxidation of enones by $\mathrm{H}_{2} \mathrm{O}_{2}$, were quite different from Michael addition of nitromethane tp cyclopentenone, described in the present article).

Our catalyst was prepared by a different experimental protocol from those reported in the literature. ${ }^{22}$ The employed precursor $(\mathrm{SiCl})$ reacts with the imine nitrogen of the TMG molecule (equation 1). The synthesized silylant agent (SiTMG) was used with the objective to modify silica in order to obtain a solid catalyst.<smiles>CN(C)C(=N)N(C)C</smiles><smiles>CCN(C)C(=O)N(C)C(=NCCC[Si](OC)(OC)OC)N(C)C</smiles>

The general procedure for the synthesis of the catalyst is idealized in a hexagonal mesoporous silica modified with SiTMG through a neutral template at room temperature. The normal synthetic procedure used required tetraethylorthosilicate (TEOS) and SiTMG solubilization in a large amount of water in order to cause complete hydrolysis of all methoxy and ethoxy groups in the presence of the n-dodecylamine template. The amine surfactant micelles guide the formation of the silanol groups around the polar head of the micelle. Outside each pore, the hydrolysed silicon atoms form siloxane groups, resulting in a crosslinked framework. After synthesis, the n-dodecylamine was removed by extraction with hot ethanol in a Soxhlet system to form the mesoporous catalyst named CatTMG.

The content of organic groups was determined by TG analysis from residual data (Figure 1). Only one wellcharacterized mass loss was observed in the TG curve, which started at $110{ }^{\circ} \mathrm{C}$ and finished at $950{ }^{\circ} \mathrm{C}$. This thermogravimetric curve presented a mass loss of $21.04 \%$, which is related to decomposition of organic pendant group, corresponding to $1.35 \mathrm{mmol}$ of TMG content per gram of silica (CatTMG). The surface area analysis showed that the CatTMG presented a very high surface area of $811 \pm 75 \mathrm{~m}^{2} \mathrm{~g}^{-1}$.

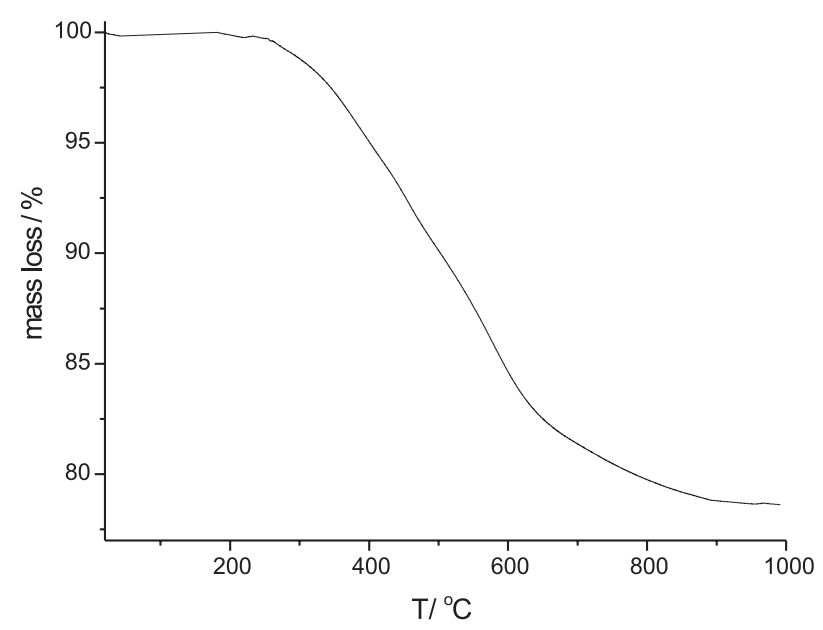

Figure 1. Thermogravimetric curve of CatTMG.

The infrared spectrum obtained for the CatTMG catalyst is shown in Figure 2. Typical silica bands associated with the main inorganic backbone can be clearly observed: $i$ ) a large broad band between 3400 to $3200 \mathrm{~cm}^{-}$ ${ }^{1}$ attributed to the presence of the O-H stretching frequency of silanol groups bonded to the inorganic structure, and also hydrogen bonds between adsorbed water and silanol and between adsorbed water and nitrogen sites of tetramethylguanidine, $\mathrm{ii}$ ) well-defined peaks at 2915 and $2840 \mathrm{~cm}^{-1}$ assigned to the $\mathrm{C}-\mathrm{H}$ stretching of tetrahedron carbon $\mathrm{iii}$ ) the band at $1650 \mathrm{~cm}^{-1}$ assigned to angular vibration of water molecules bonded to the inorganic backbone; $i v$ ) a peak at $1470 \mathrm{~cm}^{-1}$ attributed to $\mathrm{C}-\mathrm{N}$ 


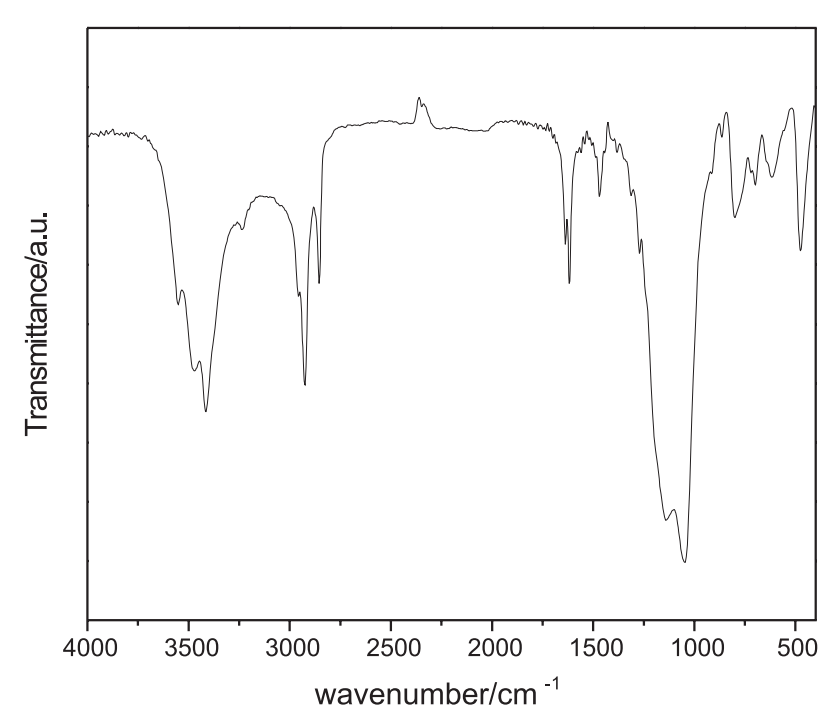

Figure 2. Infrared spectrum of CatTMG.

stretching of tetramethylguanidine; $v$ ) the intense band related to the siloxane asymmetric stretching of these groups $\left(v_{\text {as }}\right.$ Si-O-Si) at 1140 and $1050 \mathrm{~cm}^{-1} ;$ vi) a shoulder band assigned Si-O-H bending frequency at $915 \mathrm{~cm}^{-1}$ and vii) another peak at $480 \mathrm{~cm}^{-1}$ attributed to $\delta \mathrm{O}-\mathrm{Si}-\mathrm{O}$ bending. The appearance of such bands is in agreement with the formation of TMG attached to the silica structure. ${ }^{19}$

The solid state ${ }^{29} \mathrm{Si}$ NMR spectra of both materials confirm that the covalent bond formed between the silylant agents and silanol groups is dispersed onto the silica gel surface, as shown in Figure 3. The spectrum presents four peaks located at $-54,-62,-96$ and -104 $\mathrm{ppm}$. The first one is assigned to the silicon atom of the silylant agent bonded to one $\mathrm{OH}$ group, thus forming the structure, $\mathrm{RSi}(\mathrm{OSi})(\mathrm{OH})_{2}$, usually named as the $\mathrm{T}^{2}$

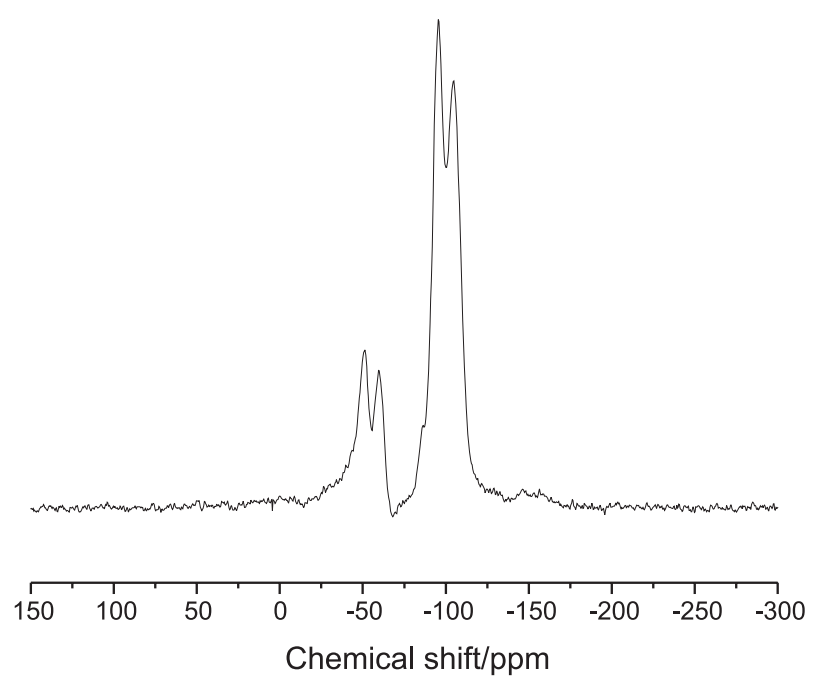

Figure 3. ${ }^{29} \mathrm{Si} \mathrm{CP} / \mathrm{MAS}$ NMR solid state spectrum of CatTMG. signal. The peak at -62 is assigned to $\mathrm{RSi}(\mathrm{OSi})_{3}$, the $\mathrm{T}^{4}$ signal. Both signals confirm that the organic groups were covalently bonded onto the silica surface. The other two peaks are attributed to pure surface signals described as: i) $\mathrm{Si}(\mathrm{OSi})_{4}, \mathrm{Q}^{4}$ at $-104 \mathrm{ppm}$; ii) surface signal, $\mathrm{Si}(\mathrm{OSi})_{3} \mathrm{OH}, \mathrm{Q}^{3}$ at $-96 \mathrm{ppm}^{19,23}$

Important information about immobilization of pendant groups on the inorganic structure of the catalyst can be obtained through solid state ${ }^{13} \mathrm{C}$ NMR spectra, as presented in Figure 4. Thus, the CatTMG spectrum is consistent with the chemical modification of the silica surface with the alkyl tetramethylguanidine group. A series of signals with chemical shifts in the range 11$160 \mathrm{ppm}$ appeared, presenting well-formed peaks at 11.2; 22; 32; 48 and $160 \mathrm{ppm}$, which are assigned to the carbons labeled in Figure 4. These peaks help to conclude that the alkyl chain and the guanidine unit were in fact bonded to the silicon atom, since the expected chemical shifts were observed.

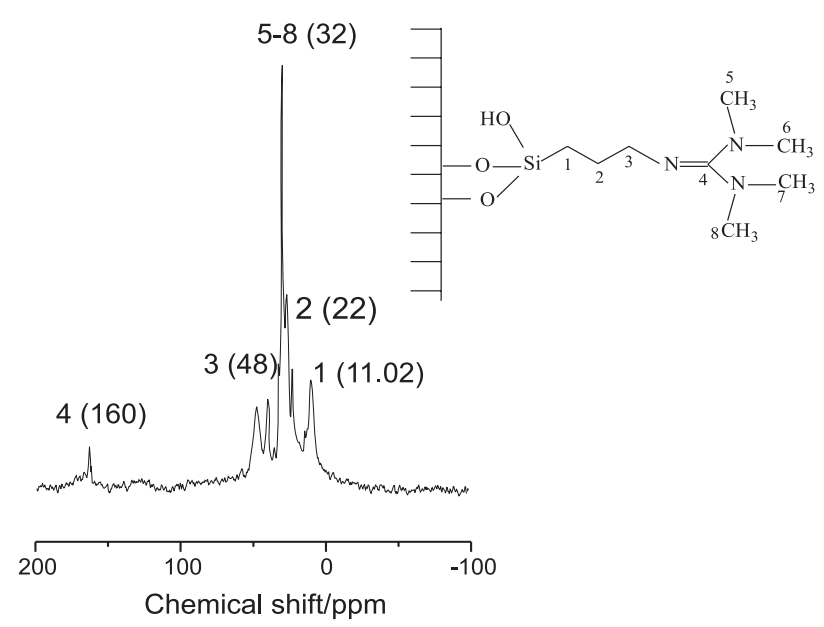

Figure 4. ${ }^{13} \mathrm{C}$ CP/MAS NMR solid state spectrum of CatTMG.

\section{Catalytic results}

The termination of reaction between nitromethane and cyclopentenone was determined by thin layer chromatography, which occurred at $3 \mathrm{~h}$. The product was characterized by ${ }^{1} \mathrm{H}$ NMR (Figure 5), which resulted in a series of signals with chemical shift in the range 1.674.56 ppm: 1.67-1.78 (m, 1H); 1.97-2.07 (q, 1H); 2.19$2.30(\mathrm{~m}, 2 \mathrm{H}) ; 2.30-2.47(\mathrm{~m}, 1 \mathrm{H}) ; 2.50-2.59(\mathrm{q}, 1 \mathrm{H}) ; 2.93-$ $3.10(\mathrm{~m}, 1 \mathrm{H})$ and $4.48-4.56(\mathrm{~d}, 2 \mathrm{H})$, consistent with published spectra. ${ }^{24}$

One of the advantages of this reaction catalysed by CatTMG is the relatively low reaction time. The kinetic studies (Figure 5) showed that the reaction reached the equilibrium at $3 \mathrm{~h}$ with a yield of $98 \%$ under almost equimolar conditions, while a similar reaction described 


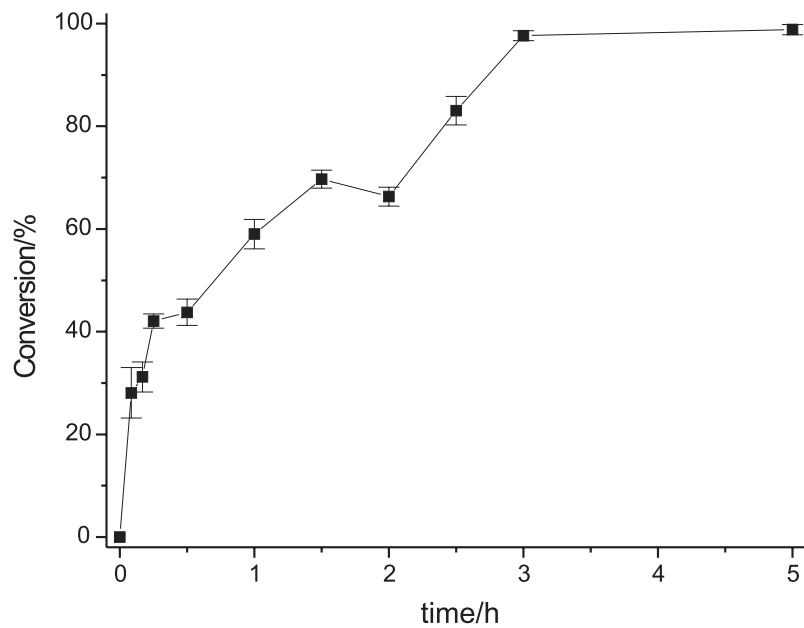

Figure 5. Kinetic studies of nitromethylcyclopentanone formation under equimolar condition, at $50{ }^{\circ} \mathrm{C}$ in $\mathrm{EtOH}$.

in the literature (between cyclohexenone and nitromethane) required a much larger excess of nitromethane, a temperature of $90{ }^{\circ} \mathrm{C}$ and a reaction time of $20 \mathrm{~h}$ by using propylamines supported on silica. ${ }^{10}$

In order to understand this heterogeneous catalysis, the Langmuir-Hinshelwood kinetic model was applied to evaluate this reaction, ${ }^{25,26}$ as represented in Figure 6.

$r_{L H}=\frac{d C}{d t}=\frac{k K C}{1+K C}$

Where $r_{\mathrm{LH}}$ is the reaction rate, $\mathrm{k}$ is the kinetic constant, $\mathrm{K}$ is the Langmuir adsorption constant and $\mathrm{C}$ is the concentration of formed product.

According to the Langmuir-Hinshelwood model, the number of surface adsorption site is fixed at the equilibrium, and only one substrate may bind at each

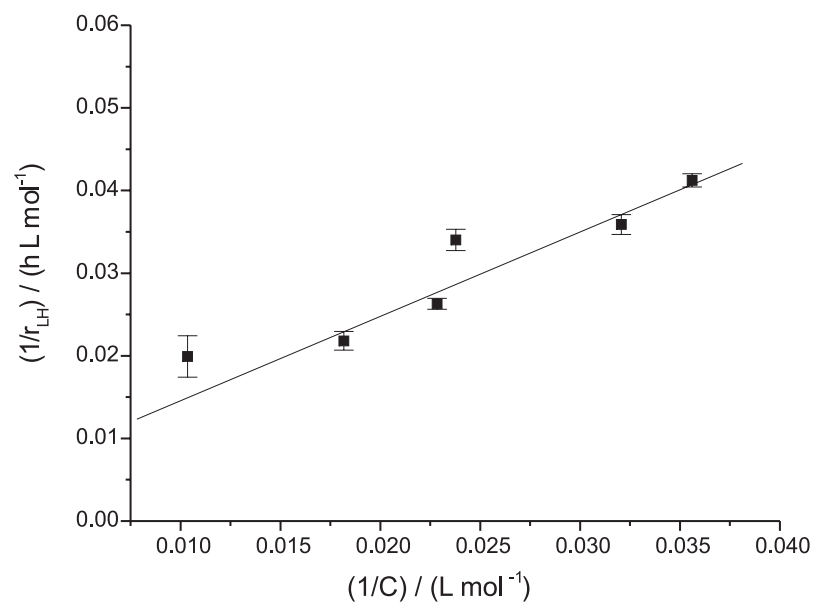

Figure 6. Langmuir-Hinshelwood kinetic model of the reaction between cyclopentenone and nitromethane catalysed by CatTMG.

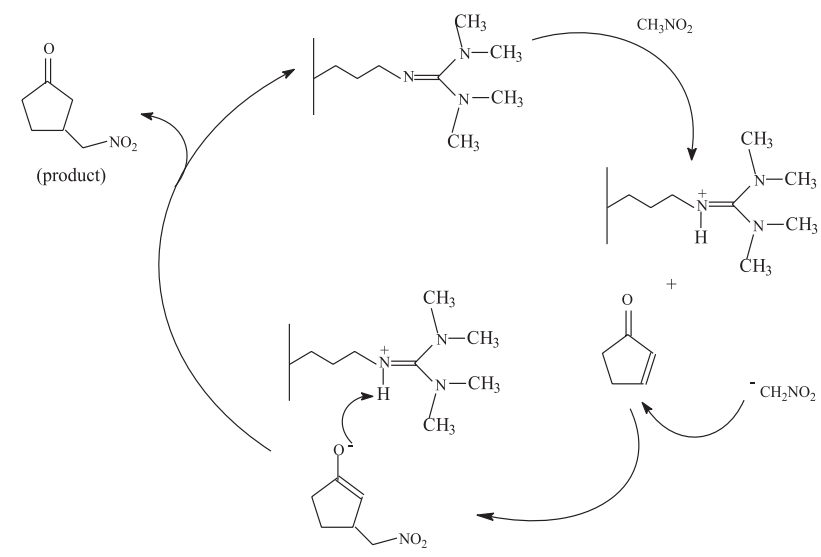

Figure 7. A hypothesized catalytic cycle of the CatTMG promoted nitromethane addition to cyclopentenone.

surface site. Thus, the heat of adsorption by substrate is equal for each site and it is independent of surface coverage and there are no interactions between adjacent adsorbed molecules. Indeed, the addition of nitromethane and cyclopentenone depends on the adsorption of reactants onto the CatTMG surface, as well of the reaction rate.

Values for $\mathrm{k}=229.36 \pm 16.35 \mathrm{~mol} \mathrm{~L}^{-1} \mathrm{~h}^{-1}$ and $\mathrm{K}=4.27$ $\pm 0.33 \mathrm{~L} \mathrm{mmol}^{-1}$ were obtained from the data in Figure 6 . These results showed that the adsorption is slow, while the reaction is rapid. Thus, the Langmuir-Hinshelwood model of this reaction suggests that the kinetics depend on the adsorption of the reactants onto the CatTMG surface. The mechanism proposed for the catalytic process is shown in Figure 7.

The catalytic efficiency of the production of nitromethylcyclopentanone at $3 \mathrm{~h}$ reaction presented a yield of around 98\%. Repeated Michael addition reactions were successively performed for fifteen cycles (in triplicate) under the above-reported conditions. The catalyst was removed after each cycle, washed with ethanol and reintroduced into the system with a new batch of nitromethane and cyclopentenone and the reaction was repeated under identical conditions. The production of nitromethylcyclopentanone presented a yield of $98 \%$ even after 15 cycles of reuse, attesting to the excellent ability of this material in catalysing this reaction.

Another important aspect of this methodology is that the reactants are present in equimolar amounts. Thus, this addition is directly linked to the atom economy concept, ${ }^{27}$ which is based on the amount of starting materials and reagents incorporated into a desired product. Thus, minimising the production of by-products or waste and makes the process more atom efficient, ${ }^{27}$ satisfying many principles of green chemistry. ${ }^{28}$ 


\section{Conclusions}

In summary, we report a convenient approach for preparing tetramethylguanidine attached to silica gel and its use as a basic agent for the Michael addition between nitromethane and cyclopentenone. The reaction presented an excellent yield at $3 \mathrm{~h}$ using mild temperatures, equimolar conditions and maintained $98 \%$ of product conversion yield after fifteen catalytic cycles. The new catalyst also presented the advantage of easy recycling, a key principle of green chemistry. These promising results should find application in other Michael addition reactions.

\section{Acknowledgments}

The authors acknowledge FUNPE, FINATEC and to FINEP/CTINFRA (0970/01) for financial support. E.D., A.G.S.P. and J.D.T. express their appreciation for fellowships from CNPq and CAPES.

\section{References}

1. Ballini, R.; Fiorini, D.; Palmieri, A.; Tetrahedron Lett. 2004, 45, 7027.

2. Ballini, R.; Synlett 1999, 7, 1009.

3. Ballini, R.; Petrini, M.; Tetrahedron 2004, 60, 1017.

4. Bakuzis, P.; Bakuzis, M. L. F.; Weingartner, T. F.; Tetrahedron Lett. 1978, 2371.

5. Stach, H.; Hesse, M.; Tetrahedron 1988, 44, 1573.

6. Bhattacharya, A.; Purohit, V. C.; Rinaldi, F.; Org. Process Res. Dev. 2003, 7, 254.

7. Ballini, R.; Bosica, G.; Fiorini, D.; Palmieri, A.; Petrini, M.; Chem. Rev. 2005, 105, 933.

8. Ono, N.; The Nitro Group in Organic Synthesis; Wiley-VCH: New York, 2001.
9. Ballini, R.; Fiorini, D.; Gil, M. V.; Palmieri, A.; Tetrahedron 2004, 60, 2799.

10. Macquarrie, D. J.; Maggi, R.; Mazzacani, A.; Sartori, G.; Sartorio, R.; Applied Catal., A 2003, 246, 183.

11. Sercheli, R.; Vargas, R. M.; Sheldon, R. A.; Schuchardt, U.; J. Mol. Catal., A 1999, 148, 173.

12. Jal, P. K.; Patel, S.; Mishra, B. K.; Talanta 2004, 62, 1005.

13. Prado, A. G. S.; Arakaki, L. N. H.; Airoldi, C.; Green Chem. 2002, 4, 42.

14. DeOliveira, E.; Prado, A. G. S.; J. Colloid Interface Sci. 2005, 291, 53.

15. Renard, G.; Mureseanu, M.; Galarneau, A.; Lerner, D. A. Brunel, D.; New J. Chem. 2005, 29, 912.

16. Prado, A. G. S.; Sales, J. A. A.; Carvalho, R. M.; Rubim, J. C.; Airoldi, C.; J. Non-Cryst. Solids 2004, 331, 61.

17. Jackson, T.; Clark, J. H.; Macquarrie, D. J.; Brophy, J. H.; Green Chem. 2004, 6, 193.

18. Clark, J. H.; Acc. Chem. Res. 2002, 35, 791.

19. Prado, A. G. S.; Miranda, B. S.; Dias, J. A.; Colloids Surf., A 2004, 242, 137.

20. Schuchardt, U.; Sercheli, R.; Vargas, R. M.; J. Braz. Chem. Soc. 1998, 9, 199.

21. Brunel, D.; Blanc, A. C.; Galarneau, A.; Fajula, F.; Catal. Today 2002, 73, 139.

22. Blanc, A. C.; Macquarrie, D. J.; Valle, S.; Renard, G.; Quinn, C. R.; Brunel, D.; Green Chem. 2000, 2, 283.

23. Albert, K.; Bayer, E.; J. Chromatogr. 1991, 544, 345.

24. Hanessian, S.; Pham, P.; Org. Lett. 2000, 2, 2975.

25. Prado, A. G. S.; Faria, E. A.; SouzaDe, J. R.; Torres, J. D.; J. Mol. Catal., A 2005, 237, 115.

26. Qu, L.; Prins, R.; J. Catal. 2002, 207, 286.

27. Trost, B. M.; Science 1991, 254, 1471.

28. Prado, A. G. S.; Quim. Nova 2003, 26, 738.

Received: January 5, 2006 Published on the web: July 13, 2006 